\title{
Los mamíferos del Mioceno y Plioceno de Espinar (Cusco): expedición y resultados preliminares del proyecto
}

Julia Tejada, Diego Báez, Jorge Gamarra y Rodolfo Salas-Gismondi

\section{(2) OpenEdition Journals}

Edición electrónica

URL: http://journals.openedition.org/bifea/2714

DOI: 10.4000/bifea.2714

ISSN: 2076-5827

Editor

Institut Français d'Études Andines

Edición impresa

Fecha de publicación: 1 agosto 2009

Paginación: 359-364

ISSN: 0303-7495

\section{Referencia electrónica}

Julia Tejada, Diego Báez, Jorge Gamarra y Rodolfo Salas-Gismondi, «Los mamíferos del Mioceno y Plioceno de Espinar (Cusco): expedición y resultados preliminares del proyecto », Bulletin de l'Institut français d'études andines [En línea], 38 (2) | 2009, Publicado el 01 febrero 2010, consultado el 18 noviembre 2020. URL : http://journals.openedition.org/bifea/2714 ; DOI : https://doi.org/10.4000/ bifea. 2714

Les contenus du Bulletin de l'Institut français d'études andines sont mis à disposition selon les termes de la licence Creative Commons Attribution - Pas d'Utilisation Commerciale - Pas de Modification 4.0 International. 


\title{
Los mamíferos del Mioceno y Plioceno de Espinar (Cusco): expedición y resultados preliminares del proyecto
}

\author{
Julia Tejada*, ** \\ Diego Báez ${ }^{* * *}$ \\ Jorge Gamarra*** \\ Rodolfo Salas-Gismondi*
}

En mayo del presente año, como parte del proyecto de investigación «Primera fauna nativa del Mio-Plioceno del Perú (Espinar, Cusco): un vistazo a la historia evolutiva de Perú y Bolivia» se realizó una expedición paleontológica y geológica a la altiplanicie Yauri que reveló la presencia de nuevos vertebrados fósiles y la existencia de localidades con singulares grados de preservación.

Los vertebrados registrados en la provincia de Espinar estaban, hasta hace poco, constituidos exclusivamente por varios especímenes de gliptodontes (identificados dentro de las subfamilias Hoplophoriinae y Glyptodontinae), una pelvis de Phyllophaga no identificada y un esqueleto subcompleto de un toxodonte correspondiente al género Posnanskytherium (Tejada et al., 2009). Nuestra última expedición amplió este registro probando la existencia de más especímenes de Posnanskytherium y al menos dos familias de Phyllophaga: un cráneo subcompleto de Mylodontidae y el extraordinario esqueleto completo de un Megatheriidae

* Instituto Francés de Estudios Andinos (IFEA), Av. Arequipa 4500, Lima 18, Perú. Email: juliatejada@gmail.com

** Museo de Historia Natural - UNMSM, Departamento de Paleontología de Vertebrados, Av. Arenales 1256, Lima 14,Perú. Email: rodsalasgis@yahoo.com

*** E.A.P. Ingeniería Geológica, Av. Venezuela s/n, Universidad Nacional Mayor de San Marcos (UNMSM), Lima-Perú. Email: dbaez25@gmail.com

**** Instituto Regional de Cultura, Cusco (INC-CUS). Email: jorgeluisgamarragamio@yahoo.es 
referido al género Megatherium (fig. 1). La marcada predominancia de xenartros en esta fauna no es sorprendente pues estos constituían parte importante de las faunas sudamericanas durante el Cenozoico. Un hecho sí inusual es la ausencia de otros taxa también comunes del Terciario sudamericano (e.g., litopternos, notoungulados mesotéridos y hegetotéridos, etc.), ausencia probablemente causada por el corto tiempo de investigación en la zona.

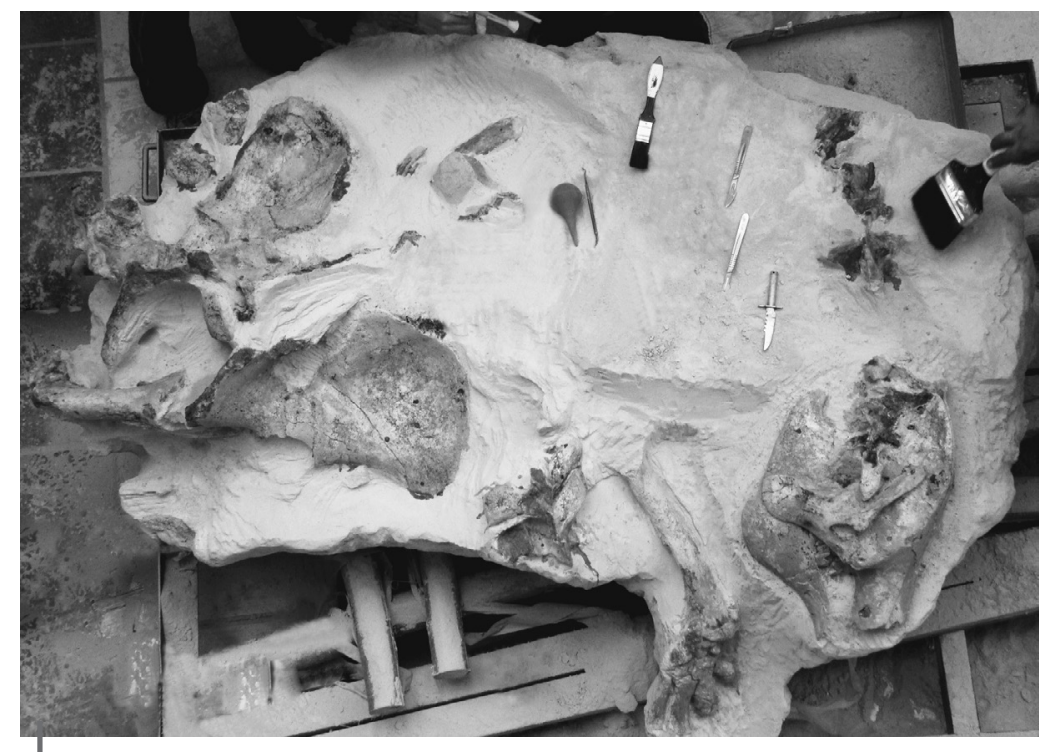

Figura 1 - Preparación del esqueleto de Megatherium sp. descubierto en niveles de la Fm Yauri en la ciudad de Espinar

Foto: R. Salas

\section{GEOLOGÍA Y EDAD}

La zona de estudio corresponde al apilamiento de series sedimentarias cuyas edades van desde el Mioceno hasta el Holoceno en la cuenca intramontañosa denominada Descanso-Yauri. Esta cubeta sedimentaria pertenece a un conjunto de cuencas localizadas a lo largo de la zona de transición entre el Altiplano y la Cordillera Occidental (Cerpa et al., 2004). Tiene una orientación NO-SE, extendiéndose por cerca de $2000 \mathrm{~km}^{2}$ entre las localidades de El Descanso, Yauri, Checca, Quehue, Santa Lucía de Pichigua, Alto Pichigua, Héctor Tejada, Ocoruro y Tintaya. Los restos óseos, descubiertos en el área proceden de las Formaciones (Fm) Casablanca y Yauri (De La Cruz, 1995; Fm El Descanso Miembro Principal y Fm El Descanso Miembro Cuspidal de Cerpa et al., 2004, respectivamente). Litológicamente estas series sedimentarias son muy parecidas: la Fm Casablanca consta de areniscas feldespáticas blanquecinas y rojizas, areniscas cuarzosas limpias, tobas retrabajadas, conglomerados polimícticos con clastos de cuarcita, calizas y volcánicos, así como alternancias de bancos calcáreos de hasta 0,5 m (Alto 
Pichigua) que indican medios fluviales trenzados de alta energía y sistemas lacustres esporádicos; la Fm Yauri presenta una sedimentación fina, lutitas oscuras bien laminadas alternadas con limolitas y areniscas feldespáticas blanquecinas, calizas blancas con laminación algárea, niveles turbidíticos, escasas areniscas cuarzosas limpias y conglomerados con clastos de cuarcitas y volcánicos que indican medios lacustres de poca energía con esporádicos sistemas fluviales o canales.

De la Cruz (1995) y Cerpa et al. (2004) coinciden en ubicar la toba Yauri como límite estratigráfico entre las Fm Casablanca y Yauri (De la Cruz, 1995) o como límite entre la Fm El Descanso Miembro Principal y Fm El Descanso Miembro Cuspidal. Dataciones Ar/Ar obtenidas de esta toba indican una edad aproximada de 12 Ma (Cerpa et al., 2004). En base al cartografiado, seguimiento de superficies de discontinuidad principales (diferenciables de las discordancias intraformacionales), levantamiento de columnas al detalle y estudios paleontológicos de vertebrados preliminares, se propone en este trabajo que la toba Yauri corresponde a un nivel piroclástico dentro de las series de la Fm Casablanca. En función de esta hipótesis, la Fm Casablanca:

(1) tendría una extensión SO mayor a la mostrada en el mapa geológico (De la Cruz, 1995);

(2) estaría limitada hacia el tope por una discordancia angular con la sobreyaciente Formación Yauri (observada claramente en el cerro Pucará, corte del río Salado en el desvío hacia Alto Pichigua);

(3) sería correlacionable en parte con niveles de la Formación El Descanso Miembro Cuspidal de Cerpa et al. (2004).

Así, la localidad de Alto Pichigua se ubicaría estratigráficamente en la Fm Casablanca, pero por encima de la toba y podría alcanzar el Mioceno superior. En cuanto a la suprayacente Fm Yauri, su ubicación estratigráfica y, principalmente, la asociación faunística descubierta sugieren que fue depositada en el Plioceno inferior-medio.

\section{VERTEBRADOS FÓSILES}

Los perezosos fósiles son bien conocidos en Sudamérica, sobretodo aquellos provenientes del SALMA Santacruzense de Argentina (Mioceno temprano) y del SALMA Lujanense (Pleistoceno medio y tardío). Gran número de las especies pleistocénicas están representadas y definidas en base a numerosos especímenes, mientras que taxa de edades más antiguas se conocen tan solo por restos fragmentarios, hecho que limita el correcto entendimiento de su historia evolutiva. Por ejemplo, existe un importante vacío de información entre las formas basales de la familia Megatheriidae (e.g., Megathericulus, Mioceno medio), y sus géneros más derivados presentes en el Pleistoceno (i.e., Megatherium y Eremotherium). En base a restos fragmentarios, Saint-André \& De luliis (2001) reportaron la especie más antigua del género Megatherium, M. altiplanicum, procedente del Plioceno del Altiplano boliviano (SALMA Montehermosense). La presencia de características 
derivadas, compartidas entre $M$. altiplanicum y $M$. americanum, sugieren que la evolución de este clado podría haberse producido en la región altiplánica a inicios del Plioceno (Saint-André \& De luliis, 2001).

El Megatherium de Espinar (Fm Yauri, Plioceno; fig. 1) es de tamaño pequeño, semejante a M. altiplanicum —la especie de Megatherium más pequeña existentepero posee caracteres que lo ubicarían fuera del clado conformado por $M$. altiplanicum y M. americanum (e.g., la presencia de premaxilares no fusionados). El clado hermano a M. altiplanicum y M. americanum está compuesto por las especies del subgénero Pseudomegatherium que conforman el denominado linaje andino (M. sundti, M. urbinai, M. celendinense, M. medinae y M. tarijense; Pujos, 2006). La observación preliminar indica que el Megatherium de Espinar posee caracteres presentes en las especies del linaje andino que requieren ser evaluadas en relación a su valor filogenético. El espécimen, actualmente en proceso de preparación, es un esqueleto virtualmente completo en conexión anatómica. Definitivamente, su antigüedad y estado de conservación servirá para comprender el origen y evolución del género Megatherium. La presencia de este megaterio basal apoya la hipótesis de Saint-André \& De luliis (2001) que sostienen que el Altiplano-Puna constituye una zona de evolución in situ para los Megatheriinae y refutaría la de Marshall \& Semperé (1992) quienes consideran que ésta habría resultado de la migración de faunas de zonas aledañas.

El segundo registro de Phyllophaga lo compone un cráneo subcompleto asignado a la familia Mylodontidae. Los milodóntidos también han sido reportados en el Plioceno del Altiplano boliviano (Saint-André, 1994; tesis doctoral no publicada). El milodóntido de Espinar posee características afines a las observadas en milodóntidos del Altiplano boliviano, lo que reforzaría la hipótesis de una fauna endémica en esta ecorregión.

Las identificaciones de los Glyptodontidae han podido ser refinadas. Hemos comprobado la presencia del género Paraglyptodon en la ciudad de Yauri (localidad Versalles, Fm Yauri) y del género Pseudoplohophorus en el distrito de Alto Pichigua (Fm Casablanca). Nuevo material de un gliptodonte Glyptodontinae fue recuperado durante esta expedición proveniente del distrito de Huanu Huanu (fig. 2), el mismo que se encuentra alojado y en proceso de preparación en el INC del Cusco.

Otro importante descubrimiento lo constituyen nuevas localidades en la Fm Yauri con pequeños peces, hojas fosilizadas y estructuras aún no identificadas. Las facies en las que se encuentran estos restos corresponden a areniscas tobáceas granodecrecientes laminadas horizontalmente, cuyos ambientes de depositación son interpretados como sistemas lacustres y palustres de baja energía. En los mismos niveles, la existencia de lutitas oscuras es indicadora de cuerpos de agua con condiciones anóxicas, necesarias para la inusual conservación de estructuras blandas. La presencia de hojas fósiles de árboles y arbustos, sumado a la menor altitud de esta región en el Plioceno temprano y medio, son evidencias de condiciones ecológicas muy diferentes en el Altiplano en esta época. La identificación taxonómica de los fósiles vegetales dará importante información 


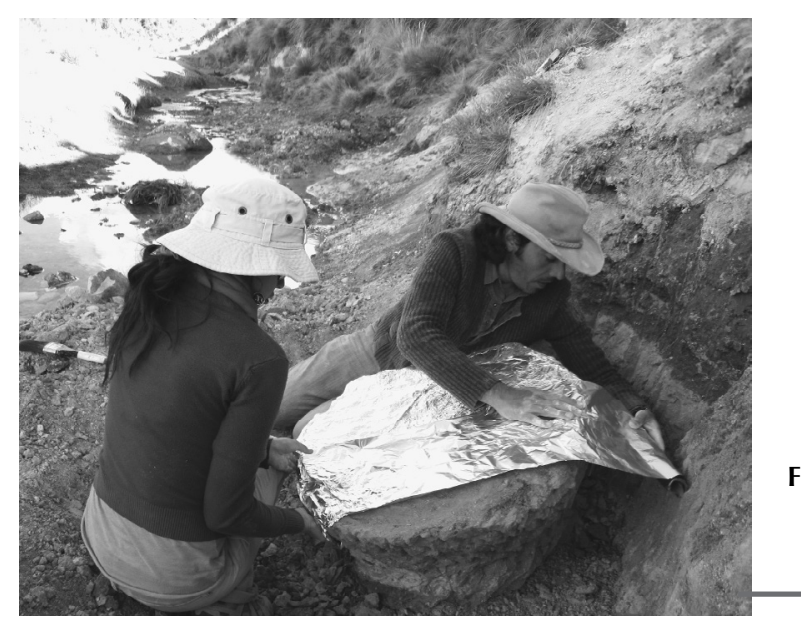

Figura 2 - Proceso de colecta de un gliptodonte Gliptodontinae procedente de la localidad de Huanu Huanu Foto: G. Vilchez

sobre el ecosistema y clima de la época. Esta preservación de taxa muy poco usuales en el registro fósil, plantean nuevas e interesantes posibilidades de investigación en el futuro.

\section{Agradecimientos}

Agradecemos a las autoridades del Municipio de Espinar por permitirnos el estudio de los fósiles de su región. Al Regidor de Cultura del Municipio de Espinar, Sr. William Inca, por su gran interés en la protección de los restos fósiles de su provincia y por su cálida hospitalidad durante nuestra estadía en Espinar. A los señores Jesús Apaza y Gregorio Agramonte del Municipio de Espinar por su gran ayuda en el reconocimiento de localidades y la preparación del material fósil. Al Sr. Hugo Huarancca, Alcalde del Distrito de Alto Pichigua, por brindarnos acceso al fósil alojado en el local municipal. Al Sr. Guido Vilchez por su asistencia logística en el trabajo de campo. Expresamos nuestra gratitud al Sr. Valentín Charca por su apoyo y compromiso en el rescate de los especímenes de Huanu Huanu. Esta expedición científica fue financiada por el Instituto Francés de Estudios Andinos.

\section{Referencias citadas}

CERPA, L., MEZA, P., CARLOTTO, V., FORNARI, M. \& SEMPERÉ, T., 2004 - Paleogeografía y evolución de la Cuenca Miocena de Descanso-Yauri (Cusco). In: Nuevas contribuciones del IRD y sus contrapartes al conocimiento geológico del sur del Perú (J. Jacay \& T. Sempere, eds.): 175-182; Lima: Publicación Especial de la Sociedad Geológica del Perú n. ${ }^{\circ} 5$.

DE LA CRUZ, N., 1995 - Geología de los cuadrángulos de Velille, Yauri, Ayaviri y Azángaro. Boletín del Instituto Geológico, Minero y Metalúrgico, Serie A: Carta Geológica Nacional, 58: 1-144. 
MARSHALL, L. G. \& SEMPERÉ, T., 1992 - Evolution of the neotropical land mammal in its geochronologic, stratigraphic and tectonic context. In: Biological Relationships between Africa and South America (P. Goldblatt, ed.): 329-392; New Haven: Yale University Press.

PUJOS, F., 2006 - Megatherium celendinense sp. nov. from the Pleistocene of the Peruvian Andes and the phylogenetic relationships of Megatheriines. Paleontology, 49 (2): 285-306.

SAINT-ANDRÉ, P.-A., 1994 - Contribution à l'étude des grands mammifères du Neogène de l'Altiplano bolivien, 659 pp.; París: Muséum National d'Histoire Naturelle. Tesis de doctorado no publicada.

SAINT-ANDRÉ, P.-A. \& IULIIS De, G., 2001 - The smallest and most ancient representative of the genus Megatherium Cuvier, 1796 (Xenarthra, Tardigrada, Megatheriidae), from the Pliocene of the Bolivian Altiplano. Geodiversitas, 23 (4): 625-645.

TEJADA, J., GAMARRA, J. \& SALAS-GISMONDI, R., 2009 - Los mamíferos del Mioceno y Plioceno de Espinar (Cusco): antecedentes y proyecto. Bulletin de I'Institut Français d'Études Andines, 38 (1): 133-135. 